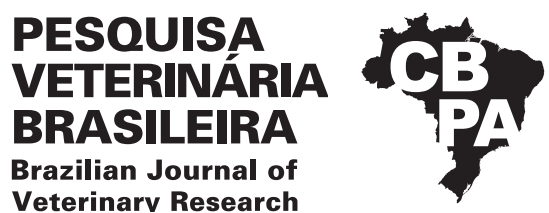

Pesq. Vet. Bras. 41:e06785, 2021

DOI: 10.1590/1678-5150-PVB-6785

Original Article

Small Animal Diseases

ISSN 0100-736X (Print)

ISSN 1678-5150 (Online)

\title{
Applicability of B-mode ultrasonography, ARFI elastography and contrast-enhanced ultrasound in the evaluation of chronic kidney disease in $\operatorname{dog} s^{1}$
}

\author{
Igor C.K. da Cruz ${ }^{2 *}$ (D), Beatriz Gasser ${ }^{2}$ (D) , Marjury Cristina Maronezi ${ }^{2}$ (D), \\ Ricardo Andrés R. Uscategui ${ }^{3}$ (D) Marcus Antônio R. Feliciano ${ }^{2,4}$ (D), \\ Luciana Cristina Padilha-Nakaghi² (D) Luiz Paulo N. Aires ${ }^{2}$ (D) \\ and Priscila D.A. da Silva² ${ }^{2}$
}

\begin{abstract}
Cruz I.C.K., Gasser B., Maronezi M.C., Uscategui R.A.R., Feliciano M.A.R., PadilhaNakaghi L.C., Aires L.P.N. \& da Silva P.D.A. 2021. Applicability of B-mode ultrasonography, ARFI elastography and contrast-enhanced ultrasound in the evaluation of chronic kidney disease in dogs. Pesquisa Veteinária Brasileira 41:e06785, 2021. Laboratório de Ultrassonografia Veterinária, Universidade Estadual Paulista "Júlio de Mesquita Filho", Via de Acesso Professor Paulo Donato Castellane s/n, Jaboticabal, SP 14884-900, Brazil. E-mail: igor_113@hotmail.com

The objective of this study was to verify the applicability of B-mode ultrasonography, ARFI elastography and CEUS in the diagnosis of chronic kidney disease and its Stages in dogs. 24 healthy dogs and 28 with CKD were included. In B-mode, the echogenicity, echotexture and cortico-medullary ratio of the kidneys were verified. By elastography, the shear-wave velocity of the cortical (SWVcort) and medullary (SWVmed) regions were determined and tissue deformity was evaluated. Wash-in, wash-out and peak enhancement (TPic) of the contrast in the renal parenchyma were calculated and homogeneity, presence of filling gaps and distinction of filling phases were evaluated by CEUS. Changes in echogenicity, echotexture and cortico-medullary ratio were observed only in sick patients. There was an increase in SWVcort in CKD, with a cutoff point $>2.91 \mathrm{~m} / \mathrm{s}$. Healthy kidneys were non-deformable and $25 \%$ had changes in gray scales. There was an increase in wash-in and TPic, changes in filling characteristics, filling failures and difficulty in distinguishing between the Stages in CEUS in CKD. It was found that dogs with CKD 2, 3 and 4 had greater SWVcort and wash-in values than CKD 1. Elastographic and CEUS changes were observed in dogs with CKD, demonstrating the applicability of ultrasonographic techniques in their diagnosis.
\end{abstract}

INDEX TERMS: B-mode, ultrasonography, ARFI, elastography, ultrasound, chronic kidney disease, dogs, stiffness, perfusion, renal, microbubbles.

RESUMO-- [Aplicabilidade da ultrassonografia modo-B, elastografia ARFI e ultrassonografia contrastada na avaliação da doença renal crônica em cães.] 0 objetivo deste estudo foi verificar a aplicabilidade da ultrassonografia modo-B, elastografia ARFI e CEUS no diagnóstico da doença

\footnotetext{
${ }^{1}$ Received on November 6, 2020.

Accepted for publication on December 3, 2020.

${ }^{2}$ Universidade Estadual Paulista "Júlio de Mesquita Filho" (Unesp), Via de Acesso Prof. Paulo Donato Castellane s/n, Jaboticabal, SP 14884-900, Brazil. *Corresponding author: igor_113@hotmail.com

${ }^{3}$ Universidade Federal do Vale do Jequitinhonha e Mucuri (UFVJM), Av. Universitária 1000, Universitários, Unaí, MG 38610-000, Brazil.

${ }^{4}$ Universidade Federal de Santa Maria (UFSM), Av. Roraima 1000, Cidade Universitária, Camobi, Santa Maria, RS 97105-900, Brazil.
}

renal crônica e seus estágios em cães. Foram incluídos 24 cães saudáveis e 28 com DRC. Pelo modo-B, verificou-se ecogenicidade, ecotextura e relação córtico-medular dos rins. Pela elastografia, foram determinadas as velocidades de cisalhamento das regiões cortical (SWVcort) e medular (SWVmed) e foi avaliada a deformidade tecidual. Calculou-se os temos de wash-in, wash-out e pico de intensidade (TPic) do parênquima renal e avaliou-se homogeneidade, presença de falhas e distinção das fases de preenchimento por contraste por meio de CEUS. Alterações em ecogenicidade, ecotextura e relação córtico-medular foram observadas somente em pacientes doentes. Houve aumento da SWVcort na DRC, com ponto de corte $>2.91 \mathrm{~m} / \mathrm{s}$. Rins saudáveis foram não-deformáveis e $25 \%$ apresentou alterações nas escalas de cinza. Houve aumento do 
wash-in e TPic, alterações nas características de preenchimento, falhas e dificuldade para distinguir as fases de preenchimento do contraste nos rins com DRC. Verificou-se que cães com DRC graus 2, 3 e 4 tiveram valores de SWVcort e wash-in maiores que cães com DRC grau 1. Foram obsrervadas alterações elastográfica e de CEUS em cães com DRC, demonstrando a aplicabilidade destas técnicas ultrassonográficas no seu diagnóstico.

TERMOS DE INDEXAÇÃO: Ultrassonografia, modo-B, elastografia, ARFI, doença renal crônica, cães, caninos, ultrassom, rigidez, perfusão, renal, microbolhas.

\section{INTRODUCTION}

Chronic kidney disease (CKD) is an irreversible structural and functional deficiency of the kidneys (Bartges 2012). In dogs, presents high occurrence, morbidity and mortality (King et al. 2017). There is a gradual reduction in functional nephrons and homeostasis is compensated at the beginning of the process. Clinical signs appear when about one third of nephrons are lost and azotemia is observed when $75 \%$ of renal function is compromised (McGrotty 2008).

Bidimensional ultrasonography is frequently performed in nephropathic dogs, in which kidneys with CKD may show increased echogenicity, heterogeneity and loss of definition and cortico-medullary ratio (Gerber \& Volkweis 2017). However, these findings are nonspecific and it's not always possible to establish the etiology (Bhadesiya et al. 2017, Bragato et al. 2017). Still, there are no studies demonstrating the applicability of this technique in the diagnosis of CKD degrees.

Elastography is a technique that allows assessment of tissue stiffness (Holdsworth etal. 2014). In humans with CKD, increased stiffness of the renal parenchyma has been observed through elastography and it was suggested that it was due to the presence of fibrotic tissue deposited during healing process (Asano et al. 2017). Holdsworth et al. (2014) described characteristics of acoustic radiation force impulse (ARFI) elastography in the canine healthy kidneys and stated that the renal cortex shear wave velocity obtained (2.1-3.3m/s) were similar to humans.

Contrast-enhanced ultrasonography (CEUS) allows hemodynamic assesment and study of tissue perfusion (Dong et al. 2013). Its use has been described in human kidneys with different vascular changes, cysts, masses or disorders of renal parenchyma (Nilsson 2004). CEUS showed 96\% sensitivity to identify malignancy in human kidney injuries and $50 \%$ sensitivity to differentiate the CKD Stages (Chang et al. 2017). Waller et al. (2007) established data regarding normal canine renal perfusion using CEUS, which can be used as a reference for studies of renal diseases. Still, it was possible to early identify changes in renal perfusion in dogs with ischemic kidney injury, which can be used to monitor disease progression (Dong et al. 2013).

Considering the high prevalence of CKD in dogs, the limitations of the tests available for the early diagnosis and the need for invasive techniques for diagnostic definition, less invasive tchniques that can assist in the diagnosis of this condiction are encouraged. Believing that there was an ultrasound difference between helthy and sick kidneys, the present study aimed to verify the morphological, functional, rigidity and tissue perfusion characteristics of canine kidneys by B-mode, ARFI elastography and CEUS, in order to assist in the diagnosis of CKD and its Stages.

\section{MATERIALS AND METHODS}

This study was approved by Institutional Ethics Committee (protocol no. $018.897 / 13$ ) of the institution where it was carried out and there was free and informed consent from all the tutors of the patients included in the experiment.

All patients underwent physical examination, blood samples were collected for biochemical analysis of serum creatinine concentrations (mg/dL) and urine (using ultrasound-guided cystocentesis) to calculate the urinary protein/creatinine ratio (UP/C), necessary for the identification and classification of the chronic kidney disease (CKD) by the criteria proposed by the International Renal Interest Society (IRIS 2016). Twenty eight dogs $(10.57 \pm 7.60 \mathrm{~kg}$ and $9.56 \pm 5.47$ years) diagnosed with CKD were included, as well as 24 healthy dogs $(11.39 \pm 9.15 \mathrm{~kg}, 7.66 \pm 2.70$ years $)$ with similar ages and weights $(P=0.287$ and $P=0.9959$, respectively).

For the animals to be considered healthy, they should meet the following inclusion criteria: creatinine below $1.4 \mathrm{mg} / \mathrm{dL}, \mathrm{UP} / \mathrm{C}$ ratio less than 0.2 , with no history of urinary disorders, without pharmacological treatment in the last 30 days and presenting all exams proposed in this study within the reference parameters for the species. Dogs with CKD were classified as follows: Stage $1=$ normal creatinine, but with proteinuria (UP/C ratio greater than 0.2 ), urinary disorders or changes in renal palpation; Stage 2 = mild azotemia (creatinine 1.4-2.0mg/ $\mathrm{dL}$ ), which may be asymptomatic or with mild clinical signs; Stage $3=$ moderate azotemia (creatinine $2.1-5.0 \mathrm{mg} / \mathrm{dL}$ ) and with the presence of clinical signs; Stage $4=$ severe azotemia (creatinine greater than $5.1 \mathrm{mg} / \mathrm{dL}$ ), with systemic clinical signs. Among the animals with CKD, four (14\%) were classified as Stage 1, four (14\%) as Stage 2, six (22\%) as Stage 3 and 14 (50\%) as Stage 4.

The patients were referred for ultrasound examination, in order to perform B-mode ultrasound, ARFI (Acoustic Radiation Force Impulse) elastography and contrast-enhanced ultrasound (CEUS) of their renal structures, by an experienced evaluator (15 years old) without knowledge of the disease or graduation. ACUSSON S2000 ultrasound equipment (SIEMENS, Munich, Germany) and a $9 \mathrm{MHz}$ linear multi-frequency transducer were used.

In B-mode, the kidneys were evaluated according to the echogenicity of the cortical region compared to the hepatic parenchyma, being classified as normal when it was iso or hypoechoic and altered when hyperechogenic, in addition to echotexture (homogeneous or heterogeneous) and cortico-medullary ratio (preserved or changed).

For ARFI elastography, "Virtual Touch Tissue Quantification" software (Siemens, Minich, Germany) was used and gray tissue elastograms were obtained. The kidneys were classified according to their rigidity: lighter gray tones represented softer/deformable tissues and dark gray tones represented more rigid/non-deformable structures. The quantitative study determined the average shear wave velocity of the cortical (SWVcort m/s) and medullary (SWVmed $\mathrm{m} / \mathrm{s}$ ) regions, by obtaining three measurements in different regions of interest (ROI).

After the end of the elastographic evaluation, contrast-enhanced ultrasound was performed, using harmonic imaging software (CADENCE $^{\circledR}$ - Siemens, Munich, Germany). For this, SonoVue ${ }^{\circledR}$ contrast (Bracco, São Paulo, Brazil) was administered at a dose of $0.01 \mathrm{ml} / \mathrm{kg}$ intravenously and the resulting images were recorded for 180 seconds. In the quantitative study, the time of contrast input (wash-in), the time for peak enhancement (TPic), and the time of contrast output (wash-out) were evaluated. For qualitative study, the filling characteristics (homogeneous or heterogeneous), filling failures (absent, discrete, moderate or intense) and filling phases (distinguishable or not distinguishable) were evaluated. 
The sample number and the statistical analysis was performed using the R software (R Foundation for Statistical Computing, Vienna, Austria). For sample number, a 90\% confidence level was considered. Qualitative variables were compared between groups using Fisher's exact test. Quantitative variables were subjected to Kolmogorov-Smirnov normality test and compared by t-Student test between groups and by ANOVA in different degrees of CKD. Subsequently, the parameters that showed significant differences $(P \leq 0.05)$ were subjected to the analysis of discriminative power (CKD or healthy) through ROC curves and the cutoff value, sensitivity, specificity, area under the curve and accuracy were calculated using the model logistic regression.

\section{RESULTS}

Serum creatinine and UP/C ratio (Table 1) were higher in the CKD group $(P=0.001)$. All the parameters evaluated were similar in the right and left kidneys $(P>0.05)$ and between the ROIs $(P>0.05)$ and these measures were used without discrimination of side or studied ROIs.

In B-mode, all healthy animals showed normal echogenicity, homogeneous echotexture and preserved cortico-medullary ratio. Of the dogs with $\mathrm{CKD}, 25 \%$ had altered echogenicity, $54 \%$ had heterogeneous echotexture and in 54\% there was a change in the cortico-medullary ratio (Fig.1).

Regarding the CKD Stages, it was noted that there was a change in cortical echogenicity in $25 \%$ of kidneys with CKD Stage 1, 100\% with Stage 2, 50\% with Stage 3 and 93\% with
Stage 4 . Heterogeneity was observed in $25 \%$ of kidneys with CKD Stage 1, 75\% with Stage 2, 17\% with Stage 3 and 75\% with Stage 4 . The change in the cortico-medullary ratio was not noticed in dogs with CKD Stage 1, however it was present in $75 \%$ of Stage $2,17 \%$ of Stage 3 and $83 \%$ of Stage 4 .

On the elastogram, $100 \%$ of the healthy kidneys were shown in medium gray and non-deformable. In patients with CKD, 14\% of the kidneys appeared as light gray (less rigid), $75 \%$ as medium gray (similar to normal kidneys) and 11\% as dark gray (more rigid). In animals with CKD Stage 1, the shades of gray were light in $25 \%$ of the cases and medium in $75 \%$ of the cases. In kidneys with CKD Stage 2, 100\% were classified as medium gray. In Stage 3, 83\% of the cases were medium gray and $17 \%$ dark. As for Stage 4 kidneys, gray was light in $22 \%$, medium in $64 \%$ and dark in $14 \%$.

Table 1. Mean \pm standard deviation of clinical and laboratory characteristics of healthy dogs and with chronic kidney disease (CKD)

\begin{tabular}{cccc}
\hline Parameter & Healthy & CKD & P value \\
\hline Age (years) & $7.66 \pm 2.70$ & $9.56 \pm 5.47$ & 0.2785 \\
Weight $(\mathrm{kg})$ & $11.39 \pm 9.15$ & $10.57 \pm 7.60$ & 0.9959 \\
Creatinine $(\mathrm{mg} / \mathrm{dL})$ & $1.21 \pm 0.16$ & $7.44 \pm 8.29$ & $0.0001^{*}$ \\
UP/C ratio & $0.08 \pm 0.08$ & $4.23 \pm 4.31$ & $0.0001^{*}$
\end{tabular}

$\overline{\mathrm{UP}} / \mathrm{C}=$ urinary protein/creatinine; ${ }^{*}$ Significative by $\mathrm{t}$-Student test $(P \leq 0.05)$.
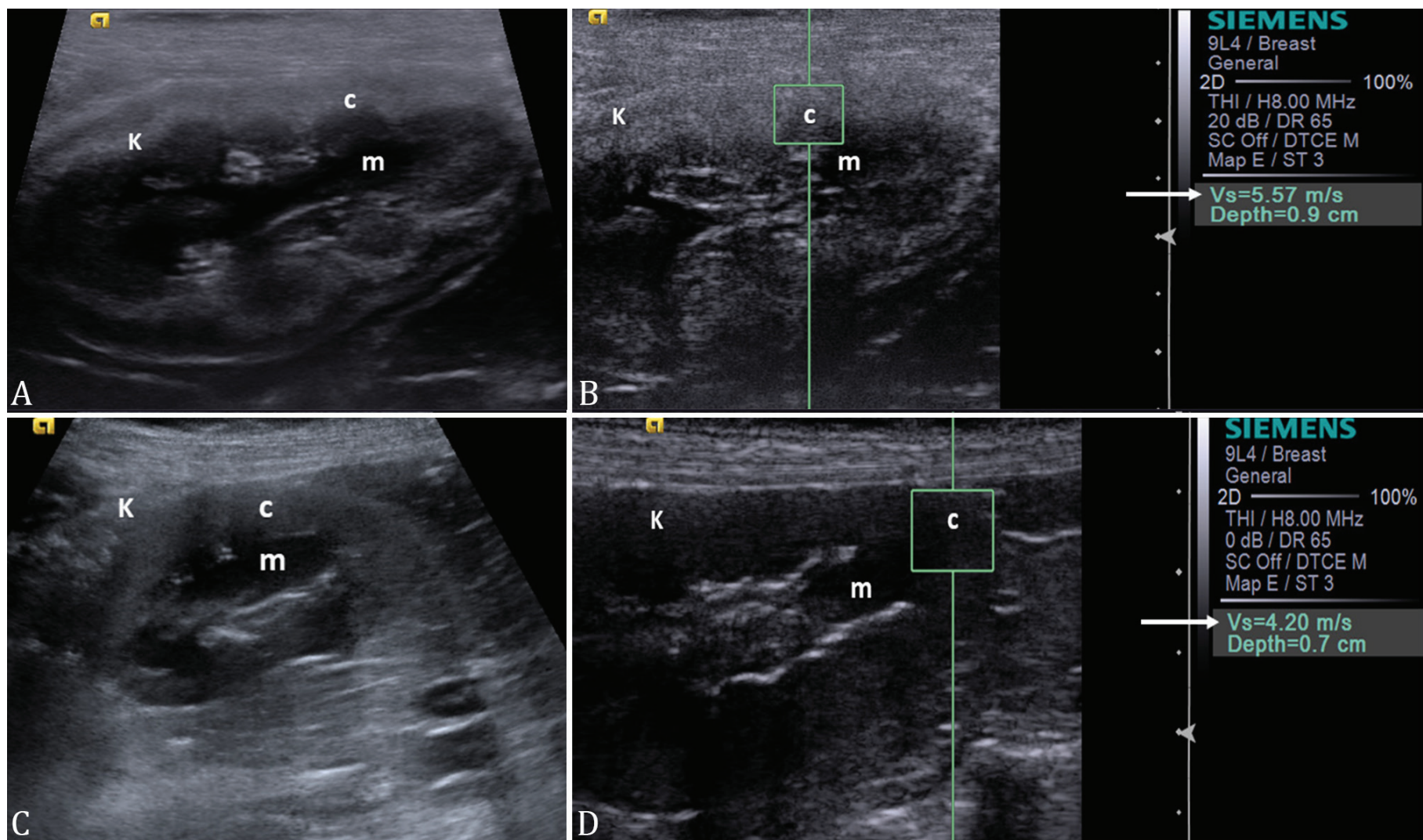

Fig.1. (A-B) Ultrasonography and ARFI elastography of canine kidney with chronic kidney disease (CKD) IV: (A) note presence of irregularity of renal surface, medular sign and córtico-medullary ratio altered; (B) note high shear-wave velocity of cortical region. (C-D) Ultrasonography and ARFI elastography of canine kidney with CKD III: (C) note increased echogenicity of cortical and loss of renal diverticulum definition; (D) note high shear-wave velocity of cortical region (arrow). Kidney (K), cortical (C), medullary (M). 
In quantitative ARFI elastography technique (Fig.1), a difference was noted between healthy and sick animals for SWVcort values $(P=0.0026)$. The SWVcort was higher in CKD $(3.89 \pm 1.27 \mathrm{~m} / \mathrm{s})$ than in healthy animals $(2.66 \pm 0.17 \mathrm{~m} / \mathrm{s})$, that is, an increased stiffness of the cortical region of the kidneys of dogs with CKD was noted. The cut-off value of SWVcort to differentiate CKD from healthy patients was $>2.91 \mathrm{~m} / \mathrm{s}$, with a sensitivity of $78 \%$, specificity of $96 \%$ and accuracy of $87 \%$. However, SWVmed was similar $(P=0.331)$ between groups.

In CEUS, the wash-in was longer in animals with CKD than in healthy dogs (Table 2). The wash-in cut-off value $>4.5 \mathrm{~s}$ is indicative of CKD, with $67 \%$ sensitivity, $83 \%$ specificity and $79 \%$ accuracy. However, there was no significant difference in the wash-out between the groups. Higher TPic values were also observed in the sick kidneys than healthy ones, with a cut-off value $>9.35 \mathrm{~s}$ being an indicator of CKD, with a sensitivity of $56 \%$, specificity of $96 \%$ and $81 \%$ accuracy.

In the qualitative assessment of CEUS (Fig.2), there was a difference between all the characteristics evaluated between

Table 2. Mean \pm standard deviation of the entrance (Washin), exit (Wash-out) and peak contrast (TPic) times in CEUS evaluation of the kidneys of healthy dogs and with chronic kidney disease (CKD)

\begin{tabular}{cccc}
\hline Parameter & Healthy & CKD & P value \\
\hline Wash-in $(\mathrm{s})$ & $3.33 \pm 1.145$ & $5.69 \pm 2.49$ & $0.0052^{*}$ \\
TPic $(\mathrm{s})$ & $6.58 \pm 1.84$ & $9.97 \pm 3.5$ & $0.0062^{*}$ \\
Wash-out $(\mathrm{s})$ & $97.75 \pm 18.86$ & $80.87 \pm 23.49$ & 0.1351 \\
\hline * Significative by t-Student test $(P \leq 0.05)$ &
\end{tabular}
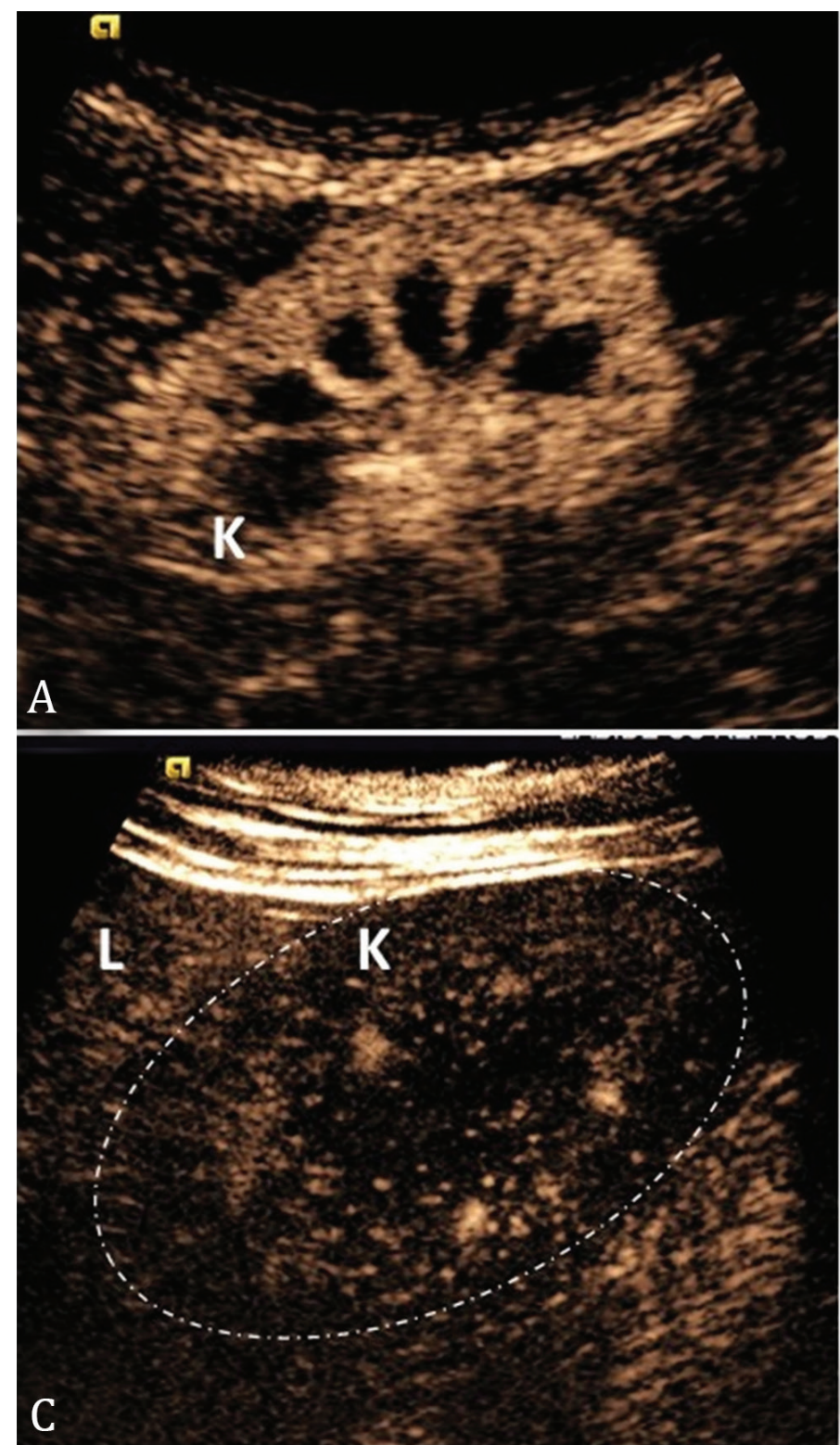
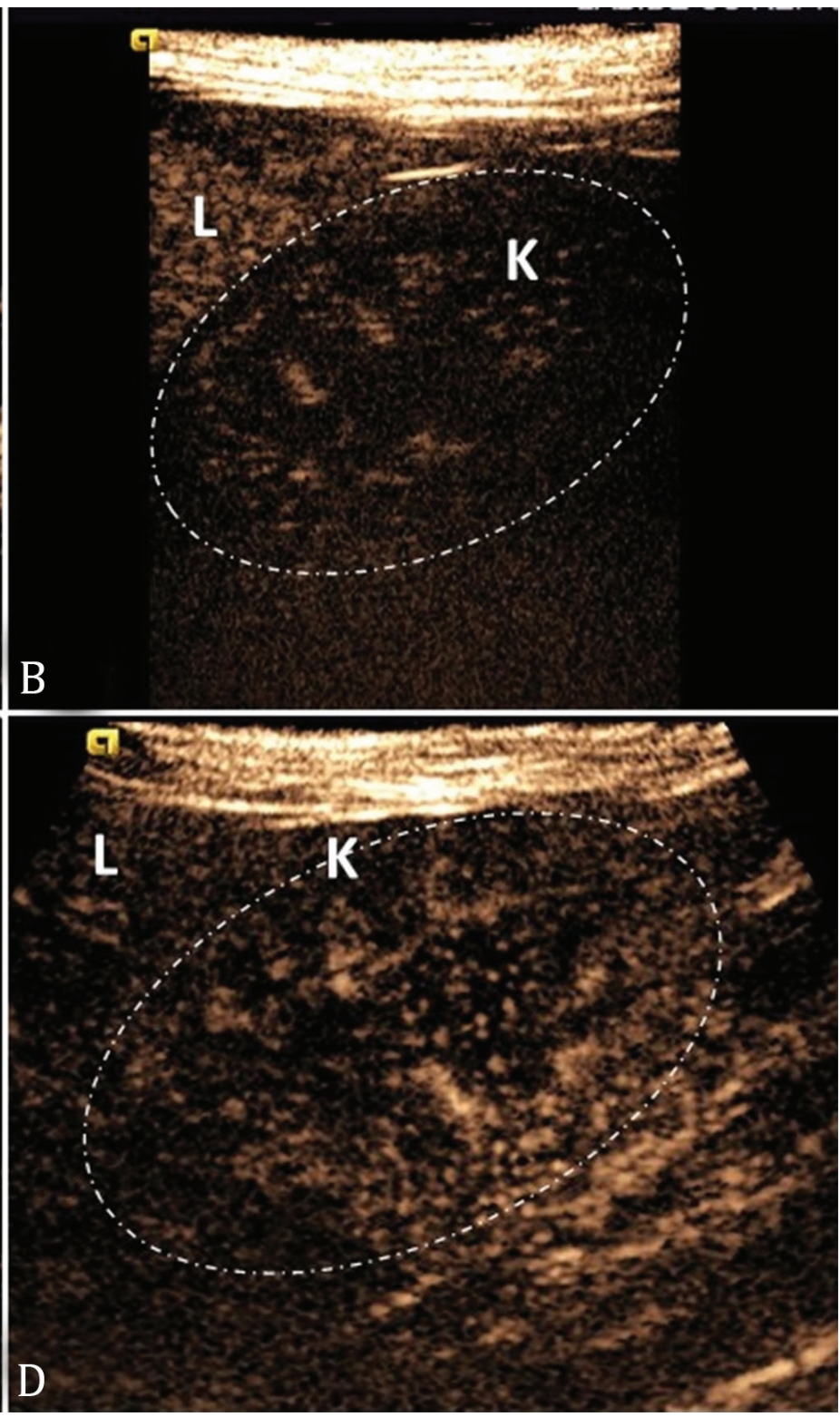

Fig.2. Contrast-enhanced ultrasound of canine kidneys. (A) Normal kidney, with homogeneous contrast filling and verification of cortical and vascular phases. (B-D) Kidneys with chronic kidney disease Stage 4. Note the failure to fill in the contrast and in the identification of the fases of contrast filling in the renal parenchyma. Kidney (K), liver (L), demarcation of altered renal structures (dotred circle). 
dogs with and without CKD (Table 3). It was observed that all the healthy kidneys showed homogeneous contrast filling, without filling flaws and with distinguishable filling phases. As for the kidneys with CKD, 75\% presented heterogeneous filling, $78.1 \%$ with filling failures and $43.8 \%$ without distinction of the phases.

Among kidneys with CKD Stage 1, 75\% presented heterogeneous filling, $75 \%$ with failures (50\% mild and $25 \%$ moderate failure) and in $25 \%$ it was not possible to distinguish the filling phases. In kidneys with CKD Stage 2, heterogeneity and filling failures were noted in $100 \%$ of cases $(50 \%$ mild and $50 \%$ moderate failure), but in no case was it difficult to distinguish the filling phases. In kidneys with CKD Stage 3, $50 \%$ were heterogeneous, $66.66 \%$ with failures $(33.33 \%$ mild and $33.33 \%$ severe failure) and $33.33 \%$ without distinction of the filling phases. In kidneys with CKD Stage 4, 100\% were heterogeneous and had filling failures (50\% moderate and $50 \%$ severe failure), and $71.43 \%$ presented difficulty in distinguishing the filling phases.

Comparing the quantitative variables of patients with CKD Stages (Table 4), SWVcort and wash-in were higher in patients with CKD Stages 2, 3 and 4 than in patients with CKD Stage 1, with the other variables being considered similar.

\section{DISCUSSION}

ARFI elastography and CEUS demonstrated applicability for the identification of CKD and in the study of its evolution in dogs, through different qualitative and quantitative characteristics and some of them showed diagnostic accuracy for the identification of this disease, such as SWVcort (87\%), Wash-in (79\%) and TPic (81\%). Thus, the results of this study are important because they demonstrate that, among the available ultrasound techniques, ARFI elastography and CEUS were more promising in the diagnostic aid of CKD in dogs, since B-mode and Doppler ultrasonography can present great variability (Bragato et al. 2017).

It was verified by the ARFI elastography that the renal structures of patients with CKD showed greater stiffness than normal tissues, which can be justified by pathophysiological changes in the affected kidneys. Considering that acute tubular necrosis is one of the most frequent renal disorders in dogs

Table 3. Qualitative classification of canine kidneys assessed by CEUS and $P$ value associating these characteristics and presence of chronic kidney disease (CKD)

\begin{tabular}{|c|c|c|c|c|}
\hline Parameter & Group & Classification & $\%$ of the kidney & $P$ value \\
\hline \multirow{4}{*}{$\begin{array}{c}\text { Fill } \\
\text { characteristic }\end{array}$} & \multirow[t]{2}{*}{ Healthy } & Homogeneous & $100 \%$ & \multirow[t]{4}{*}{$0,0001^{*}$} \\
\hline & & Heterogeneous & $0 \%$ & \\
\hline & \multirow[t]{2}{*}{ CKD } & Homogeneous & $25 \%$ & \\
\hline & & Heterogeneous & $75 \%$ & \\
\hline \multirow[t]{4}{*}{ Fill failure } & \multirow[t]{2}{*}{ Healthy } & Absent & $100 \%$ & \multirow[t]{4}{*}{$0,0001^{*}$} \\
\hline & & Present & $0 \%$ & \\
\hline & \multirow[t]{2}{*}{ CKD } & Absent & $21.9 \%$ & \\
\hline & & Present & $78.1 \%$ & \\
\hline \multirow{4}{*}{$\begin{array}{c}\text { Distinction } \\
\text { of the filling } \\
\text { phase }\end{array}$} & Healthy & Distinguishable & $100 \%$ & \multirow[t]{4}{*}{$0,0001^{*}$} \\
\hline & \multirow{3}{*}{ CKD } & Not distinguishable & $0 \%$ & \\
\hline & & Distinguishable & $56.2 \%$ & \\
\hline & & Not distinguishable & $43.8 \%$ & \\
\hline
\end{tabular}

(Sapin et al. 2016) and, consequently, fibrosis is formed during the healing process (De Camargo et al. 2006), it is justified the observed increase in stiffness. However, other injuries can also be associated with this increased stiffness, such as tubular proteinosis, chronic interstitial nephritis, mononuclear inflammatory infiltrates and glomerulosclerosis (Hall et al. 2016).

When comparing the CKD Stages, the renal structures of patients with CKD Stages 3 and 4 were more rigid in qualitative assessment than in Stages 1 and 2, in which only the most advanced grades showed dark gray elastograms. In the assessment of SWVcort, Stages 2, 3 and 4 showed greater stiffness. According to McLeland et al. (2015), the healing reaction of the cortical region in abnormal renal tissues has a correlation with the disease Stage, that is, the greater the degree of the lesion, more intense is the healing reaction and fibrosis in the affected renal tissue, corroborating with the increase in stiffness observed by elastography in the present study. Still, the fact that there was a significant increase in stiffness only in the cortical region is justified because $80 \%$ of the renal blood supply is directed to this region, which, consequently, is more predisposed to areas of ischemia with replacement of normal tissue by fibrous connective tissue during healing (Brown et al. 2016).

The increase in entry times and peak contrast enhancement observed in patients with CKD is justified by the decrease in the rate of blood flow through renal tissue, since renal tubular hypoxia has been considered an important factor in the development and progression of CKD and, considering that patients with acute kidney injury trigger renal ischemia, the chronicity of the process culminates in tubular atrophy,

Table 4. Mean \pm standard deviation (SD) of shear wave velocity of the cortical (SWVcort) and medullary (SWVmed) regions, times of entry (Wash-in), exit (Wash-out) and peak intensity (TPic) of CEUS in canine kidneys with different stages of chronic kidney disease

\begin{tabular}{|c|c|c|c|}
\hline Parameter & Stage & Mean \pm SD & $P$ value \\
\hline \multirow[t]{4}{*}{ SWVcort } & 1 & $2.49 \pm 0.40^{\mathrm{a}}$ & $0.0260 *$ \\
\hline & 2 & $4.36 \pm 1.08^{b}$ & \\
\hline & 3 & $4.66 \pm 1.15^{b}$ & \\
\hline & 4 & $3.82 \pm 1.11^{b}$ & \\
\hline \multirow[t]{4}{*}{ SWVmed } & 1 & $1.80 \pm 0.46^{\mathrm{a}}$ & 0.6090 \\
\hline & 2 & $2.09 \pm 0.90^{\mathrm{a}}$ & \\
\hline & 3 & $2.22 \pm 0.25^{\mathrm{a}}$ & \\
\hline & 4 & $2.46 \pm 1.12^{\mathrm{a}}$ & \\
\hline \multirow[t]{4}{*}{ Wash-in } & 1 & $3.25 \pm 0.50^{\mathrm{a}}$ & $0.0135^{*}$ \\
\hline & 2 & $8.00 \pm 0.00^{b}$ & \\
\hline & 3 & $6.83 \pm 3.49^{b}$ & \\
\hline & 4 & $5.79 \pm 2.61^{b}$ & \\
\hline \multirow[t]{4}{*}{ TPic } & 1 & $7.50 \pm 1.73^{\mathrm{a}}$ & 0.2740 \\
\hline & 2 & $13.00 \pm 1.41^{\mathrm{a}}$ & \\
\hline & 3 & $11.50 \pm 5.31^{\mathrm{a}}$ & \\
\hline & 4 & $10.00 \pm 3.31^{\mathrm{a}}$ & \\
\hline \multirow[t]{4}{*}{ Wash-out } & 1 & $74.25 \pm 6.55^{\mathrm{a}}$ & 0.4740 \\
\hline & 2 & $58.50 \pm 7.78^{a}$ & \\
\hline & 3 & $86.67 \pm 26.94^{a}$ & \\
\hline & 4 & $79.07 \pm 24.44^{\mathrm{a}}$ & \\
\hline
\end{tabular}


interstitial fibrosis and mononuclear inflammation (Brown et al. 2016). Thus, the most intense changes in the study of renal contrast in patients with higher degrees of CKD (Stages 2,3 and 4) are related to vascular lesions resulting from the chronicity of the disease described by Brown et al. (2016). Still, in a study by Dong et al. (2013), it was found that canine kidneys with chronic ischemic kidney disease also showed an increase in peak enhancement time, corroborating our findings.

In addition to the increase in wash-in and TPic, the kidneys of dogs with CKD also showed heterogeneous filling, with filling failures and difficulty in distinguishing between the entry, peak and exit phases. These findings may be associated with the vascular and healing changes described in CKD, and may be correlated with the presence of ischemic, inflamed or fibrotic areas (Brown et al. 2016). Furthermore, CEUS findings are understandable since, due to the renal vascular anatomy, nephrons are entirely dependent on the blood supply to perform their function (Beeuwkes \& Bonventre 1975) and in patients with CKD there is vascular impairment, which was observed through this imaging technique in several aspects.

The quantitative data, predictive of CKD obtained in this study (SWVcort, wash-in and TPic) showed good diagnostic accuracy ( $87 \%, 79 \%$ and $81 \%$, respectively). Thus, until more accurate studies are not released, elastography and CEUS can be used as effective complementary methods for the identification of CKD and differentiation of more advanced degrees of this disease. The use of these diagnostic techniques has been increasingly implemented in the study of different organs and pathologies both in humans (Goertz et al. 2016, Schinkel et al. 2016, Goertz et al. 2019, Thaiss et al. 2019) and animals (Holdsworth et al. 2014, Maronezi et al. 2015) and it is hoped that the results obtained in this research can serve as a tool for the implementation and execution of large-scale studies, allowing the use of these non-invasive methods in the diagnosis and staging of CKD canine.

\section{CONCLUSION}

Both ARFI elastography and CEUS proved to be promising diagnostic tools for the differentiation between kidneys from healthy dogs and those with CKD, as well as for staging patients with greater severity, since it was possible to associate the increase in stiffness and changes of vascular filling with the Stages of the disease, accurately.

\section{AUTHOR CONTRIBUTIONS}

Conception and design: Marcus Antônio Rossi Feliciano, Rcardo Andrés Ramirez Uscategui, Luciana Cristina PadilhaNakaghi.

Ultrasound evaluation: Igor Cezar Kniphoff da Cruz, Beatriz Gasser, Marjury Cristina Maronezi, Luiz Paulo Nogueira Aires, Priscila Del Aguila da Silva.

Satatistical analysis: Igor Cezar Kniphoff da Cruz, Ricardo Andrés Ramirez Uscategui.

Drafting the article: Igor Cezar Kniphoff da Cruz, Marcus Antônio Rossi Feliciano, Ricardo Andrés Ramirez Uscategui.

Revising article for intellectual content: Igor Cezar Kniphoff da Cruz, Beatriz Gasser, Marjury Cristina Maronezi, Ricardo Andrés Ramirez Uscategui, Marcus Antônio Rossi Feliciano, Luciana Cristina Padilha-Nakaghi, Luiz Paulo Nogueira Aires, Priscila Del Aguila da Silva.
Acknowledgements.- The authors would like to thank the "Fundação de Amparo à Pesquisa do Estado de São Paulo" (FAPESP protocol numbers: 2017/14957-6 and 2019/15282-8) and "Conselho Nacional de Desenvolvimento Científico e Tecnológico" (CNPq) by productivity scholarship award (process 309199/2017-4). The authors also thank Jair Matos and Siemens Healthineers for technical assistance.

Conflict of interest statement.- The authors declare having no competing interests.

\section{REFERENCES}

Asano K., Ogata A., Tanaka K., Ide Y., Sankoda A., Kawakita C., Nishikawa M., Ohmori K., Kinimura M., Shimada N. \& Fukushima M. 2017. Acoustic radiation force impulse elastography of the kidneys. J. Ultrasound Med. 33(5):793801. <https://dx.doi.org/10.7863/ultra.33.5.793><PMid:24764334>

Bartges J.W. 2012. Chronic kidney disease in dogs and cats. Vet. Clin. N. Am., Small Anim. Pract. 42(4):669-692. <https://dx.doi.org/10.1016/j. cvsm.2012.04.008><PMid:22720808>

Beeuwkes R. \& Bonventre J.V. 1975. Tubular organization and vascular-tubular relations in the dog kidney. Am. J. Physiol. 229(3):695-713.<https://dx.doi. org/10.1152/ajplegacy.1975.229.3.695><PMid:1211465>

Bhadesiya C.M., Shah B.R., Mer D.R., Parikh P.V., Rao N., Pande A.M., Patel A.C., Jani R.G. \& Raval S. 2017. Studies on renal ultrasonography in azotemic dogs. Trend Biosci. 10(27):5801-5807.

Bragato N., Borges N.C. \& Fioravanti M.C.S. 2017. B-mode and Doppler ultrasound of chronic kidney disease in dogs and cats. Vet. Res. Commun. 41(4):307-315. <https://dx.doi.org/10.1007/s11259-017-9694-9> <PMid:28634673>

Brown C.A., Elliot J., Schmiedt C.W. \& Brown S.A. 2016. Chronic kidney disease in aged cats: clinical features, morphology and proposed pathogenesis. Vet. Pathol.53(2):309-326.<https://dx.doi.org/10.1177/0300985815622975> <PMid:26869151>

Chang E.H., Chong W.K., Kasoji S.K., Fielding J.R., Altun E., Mullin L.B., Kim J.I., Fine J.P., Dayton P.A. \& Rathmell W.K. 2017. Diagnostic accuracy of contrast-enhanced ultrasound for characterization of kidney lesions in patients with and without chronic kidney disease. BMC Nephrol. 18(1):266. <https://dx.doi.org/10.1186/s12882-017-0681-8> <PMid:28793871>

De Camargo M.H.B., Moraes J.R.E., Carvalho M.B., Ferraro G.C. \& Borges V.P. 2006. Alterações morfológicas e funcionais dos rins de cães com insuficiência renal crônica. Arq. Bras. Med. Vet. Zootec. 58(5):781-787. <https://dx.doi. org/10.1590/S0102-09352006000500013>

Dong Y., Wang W., Cao J., Fan P. \& Lin X. 2013. Quantitative evaluation of contrast-enhanced ultrasonography in the diagnosis of chronic ischemic renal disease in a dog model. Plos One 8(8):e70337. <https://dx.doi. org/10.1371/journal.pone.0070337><PMid:23936410>

Gerber F. \& Volkweis F.S. 2017. Diagnóstico e estadiamento da doença renal crônica em cães. Revta Cient. Med. Vet. UNICEPLAC 4(2):46-60.

Goertz R.S., Gabmann L., Strobel D., Wildner D., Shellhaas B., Neurath M.F. \& Pfeifer L. 2016. Acoustic Radiation Force Impulse (ARFI) elastography in autoimmune and cholestatic liver diseases. Ann. Hepatol. 18(1):23-29. <https://dx.doi.org/10.5604/01.3001.0012.7858> <PMid:31113596>

Goertz R.S., Schuderer J., Strobel D., Pfeifer L., Neurath M.F. \& Wildenr D. 2019. Acoustic radiation force impulse shear wave elastography (ARFI) of acute and chronic pancreatitis and pancreatic tumor. Eur. J. Radiol. 85(12):2211-2216. <https://dx.doi.org/10.1016/j.ejrad.2016.10.019> <PMid:27842669>

Hall J.A., Yerramilli M., Obare E., Yerramilli M., Almes K. \& Jewell D.E. 2016. Serum concentrations of symmetric dimethylarginene and creatinine in dogs with naturally occuring chronic kidney disease. J. Vet. Intern. Med. 30(3):794-802. <https://dx.doi.org/10.1111/jvim.13942><PMid:27103204> 
Holdsworth A., Bradley K., Birch S., Browne W.J. \& Barberet V. 2014. Elastography of the normal canine liver, spleen and kidneys. Vet. Radiol. Ultrasound 55(6):620-627. <https://dx.doi.org/10.1111/vru.12169> <PMid:24842271>

IRIS 2016. IRIS Staging of CKD (modified 2016). International Renal Interest Society, United Kingdom. Available at <http://www.iris-kidney.com/ pdf/3_staging-of-ckd.pdf> Accessed on Apr. 22, 2020.

King J.N., Font A., Rousselot J.F., Ash R.A., Bonfanti U., Brovida C., Crowe I.D., Lanore D., Pechereau Seewald W. \& Strehlau G. 2017. Effects of benazepril on survival of dogs with chronic kidney disease: a multicenter, randomized, blinded, placebo-controlled clinical trial. J. Vet. Intern. Med. 31(4):11131122. <https://dx.doi.org/10.1111/jvim.14726><PMid:28669137>

Maronezi M.C., Feliciano M.A.R., Crivellenti L.Z., Borin-Crivellenti S., Silva P.E.S., Zampolo C., Pavan L., Gasser B., Simões A.P.R., Maciel G.S., Canola J.C. \& Vicente W.R.R. 2015. Spleen evaluation using contrast enhanced ultrasonography and Doppler in dogs with subclinical ehrlichiosis. Arq. Bras. Med. Vet. Zootec. 67(6):1528-1532. <https://dx.doi.org/10.1590/1678-4162-7941>

McGrotty Y. 2008. Diagnosis and management of chronic kidney disease in dogs and cats. In Practice 30:502-507.

McLeland S.M., Cianciolo R.E., Duncan C.G. \& Quimby J.M. 2015. A comparasion of biochemical and histopathologic staging in cats with chronic kidney disease. Vet. Pathol. 52(3):524-534. <https://dx.doi org/10.1177/0300985814561095><PMid:25516066>

Nilsson A. 2004. Contrast-enhanced ultrasound of the kidneys. Eur. Radiol. 14(Supl.8):104-109. <PMid:15700338>

Sapin C.F., Silva-Mariano L.C., Bassi J.N. \& Grecco F.B. 2016. Anatomo-pathological and epidemiological analysis of urinary tract lesions in dogs. Ciência Rural 46(8):1443-1449. <https://dx.doi.org/10.1590/0103-8478cr20151235>

Schinkel A.F.L., Kaspar M. \& Staub D. 2016. Contrast-enhanced ultrasound: clinical applications in patients with atherosclerosis. Int. J. Cardiovasc. Imag. 32(1):35-48. <https://dx.doi.org/10.1007/s10554-015-0713-z> $<$ PMid:26206524>

Thaiss W.M., Bedke J., Kruck S., Spira D., Stenzl A., Nikolaou K., Horger M. \& Kaufmann S. 2019. Can contrast-enhanced ultrasound and acoustic radiation force impulse imaging characterize CT-indeterminate renal masses? A prospective evaluation with histological confirmation. World J. Urol. 37(7):1339-1346. <https://dx.doi.org/10.1007/s00345-018-2520-3> <PMid:30324296>

Waller K.R., O'Brien R.T. \& Zagzebski J.A. 2007. Quantitative contrast ultrasound analysis of renal perfusion in normal dogs. Vet. Radiol. Ultrasound 48(4):373-377. <https://dx.doi.org/10.1111/j.1740-8261.2007.00259.x> $<$ PMid:17691639> 